\title{
ANALISIS EFISIENSI PRODUKSI DAN PEMASARAN JAMBU METE DI KABUPATEN FLORES TIMUR
}

\section{ANALYSIS OF EFFICIENCY IN CASHEW FRUIT PRODUCTION AND MARKETING IN EAST FLORES REGENCY}

\author{
Yusuf $^{1}$, Masyhuri $^{2}$, M. Maksum ${ }^{3}$
}

\begin{abstract}
Cashew fruit (Anacardium Occidentale. L) is one of important annual industrial plants. The commodity is very prospective in international market. Word supply keeps increasing resulting from relatively high increase of the price. Therefore, production increase has become the farmers' objective besides profit and high price in marketing.

The research was conducted in 4 villages in Tanjung Bunga Sub-district in East Flores Regency. The aim of this research was to recognize the factors that influence the production of cashew fruit, the factors that influence the efficiency of input using of cashew fruit farming, the factors that influence the profit of cashew fruit farming, the factors that influence marketing margin from producer level to consumer and the factors that influence the efficiency of the log of cashew fruit plant.

The data used were primary data taken from 120 samples of farmers and 18 cashew fruit traders and secondary data from related offices. To analyze the data, multiple linear regression was employed using Ordinary Least Square (OLS) method with the help of Shazam program and SPSS.

Result of the analysis suggested that first, there were six factors that influenced the production of cashew fruit including acreage, population of plants, number of labor, urea fertilizer, participation of farmers, and intensity of extension; second, price alocative of cashew fruit farming was inefficient; third, profit of cashew fruit farming was influenced very much by price of urea fertilizer. price of $\mathrm{KCI}$ fertilizer and price of herbicide; fourth, the factors that influenced marketing margin was the the price at producer level and production volume; fifih. short marketing-channels had not been able to be efficient marketing channels.
\end{abstract}

Keywords : production, efficiency, marketing, margin, cashew fruit

\footnotetext{
1. Balai Pengkajian dan Teknologi Pertanian Naibonat, Litbang Pertanian

2. Fakultas Pertanian Universitas Gadjah Mada

${ }^{33}$ Fakultas Teknologi Pertanian Universitas Gadjah Mada
} 


\section{AGRO EKONOMI}

\section{PENGantaR}

Jambu Mete (Anacardium Occidentale.L) merupakan salah satu tanaman industri tahunan yang penting. Komoditi ini termasuk mata dagangan cukup andal di pasar internasional. Pemasokan dunia selalu naik, karena dipacu oleh kenaikan harga yang cenderung tinggi. Sehingga peningkatan produksi menjadi salah satu tujuan petani disamping tujuan mendapatkan keuntungan dan tingginya bagian harga yang diterima dalam pemasaran. Peningkatan produksi dan keuntungan maksimum tercapai apabila semua faktor produksi telah dialokasikan secara optimal. Pada kondisi demikian nilai produk marginal faktor produksi sama dengan harga faktor produksi tersebut (Debertin, 1986). Sementara bagian harga yang diterima petani tinggi jika tercapai efisiensi pemasaran yang dapat dilihat dari hesarnya margin pemasaran (Arshad, 1980 dan Rashid 1973).

Usahatani jambu mete mempunyai nilai strategis terutama berkenaan dengan (Ditjenbun, 1991): 1). Penyelamatan dan pelestarian asset sumberdaya pembangunan; karena jambu mete sekaligus merupakan tanaman konservasi lahan marginal, mengingat tanaman ini dapat tumbuh di mana tanamn lain tidak bisa tumbuh (Puryanto, 1993; Abdullah, 1985; dan Sugiyanto,1994). 2). Penggalian asset potensial domestik pembangunan; mengingat nilai ekonomi jambu mete cukup baik dan diversifikasi produknya cukup banyak; dan 3). Penggalangan kekuatan nasional pada akses rebut tawar (bargaining) dalam situasi perekonomian internasional yang semakin global, dengan memperhatikan keunggulan komparatif jambu mete.

Persoalan pokok yang selalu melekat adalah masalah produksi dan pemasaran (Anwar,1995). Masalah Produsi, berkenaan dengan masih berpengaruhnya faktor alam, sehingga menyebabkan tingginya peluang untuk terjadinya kegagalan produksi. Keadaan ini diperburuk oleh pola pengusahaan yang kurang intensif. Akumulasi dari semua ini mempengaruhi stabilitas dan kelestarian pasok produk yang dibutuhkan pasar disamping itu berakibat rendahnya pendapatan yang diperoleh petani. Pada sisi lain, pengusahaan yang kurang intensif berdampak pada penyerapan tenaga kerja yang kurang memadai utamanya terhadap upaya penekanan pengangguran di pedesaan (Darsono, 1996). Masalah pasar, hal ini disebabkan oleh fluktuasi prodıksi karena musiman (seasional), relatif panjangnya gestation period, sifat perishable, bulky. Usahatani jambu mente dengan skala yang kecil dan tersebar (spatial) sehingga mempertinggi biaya pengumpulan (procurement cost). Fluktuasi produksi juga dibarengi dengan fluktuasi harga.

Melihat persoalan tersebut maka penelitian ini bertujuan untuk mengetahui faktor-faktor yang memperngaruhi produksi jambu mete, faktor-faktor yang mempengaruhi keuntungan usahatani jambu mete, efisiensi penggunaan faktorfaktor produksi dalam usahatani jambu mete, mengetahui saluran pemasaran dan mengukur margin dari tingkat produsen sampai tingkat konsumen dan mengukur tingkat efisiensi pemasaran jambu mete.

\section{CARA PENELITIAN}

Dalam penelitian ini digunakan metoda purposive sampling dengan jumlah sampel sebanyak 120 petani jambu mente dan 18 pedagang gelondong mete yang diambil dari empat desa yaitu Baluk Hering, Sinamalaka, Bandona dan Painapang. 


\section{AGRO EKONOMI}

Untuk menganalisis data dalam penelitian ini digunakan analisis sebagai berikut:

1. Untuk menilai dan mengetahui hubungan serta sumbangan faktor faktor produksi dan faktor lainnya terhadap tingkat produksi jambu mete, diestimasi dengan fungsi produksi Cobb-Douglas. Untuk menaksir parameter-parameter harus ditransformasikan ke dalam bentuk double logaritma natural (ln), sehingga merupakan bentuk linear berganda yang kemudian dianalisis dengan metoda kuadrat terkecil (OLS).

$\ln Y=\ln A+b_{1} \ln X_{1} b_{2} \ln X_{2}+b_{3} \ln X_{3}+b_{4} \ln X_{4}+b_{5} \ln X_{5}+b_{6} \ln X_{6}+b_{7} \ln X_{7}+$

$$
b_{8} \ln X_{8}+b_{9} \ln X_{9}+b_{10} \ln X_{10}+b_{11} \ln X_{11}+b_{12} \ln X_{12}+b_{13} \ln _{13}+b_{14} \ln _{14}+U
$$

Keterangan :

$\mathrm{Y}=$ produksi jambu mete.

A $=$ intercep

$\mathrm{X}_{1}=$ luas lahan

b1 ...b14 = koefisien regresi

$\mathrm{X}_{2}=$ populasi tanaman

$\mathrm{U}=$ kesalahan

$\mathrm{X}_{3}=$ umur tanaman

$\mathrm{X}_{12}=$ jarak dari sarana produksi

$\mathrm{X}_{4}=$ jumlah tenaga kerja

$\mathrm{X}_{13}=$ jarak dari kebun

$\mathrm{X}_{5}=$ jumlah pupuk Urea

$\mathrm{X}_{14}=$ intensitas penyuluhan

$\mathrm{X}_{6}=$ jumlah pupuk TSP

$\mathrm{X}_{7}=$ jumlah pupuk $\mathrm{KCl}$

$\mathrm{X}_{8}=$ jumlah herbisida

$\mathrm{X}_{9}=$ pengalaman petani

$\mathrm{X}_{10}=$ tingkat pendidikan formal

$\mathrm{X}_{11}=$ tingkat partisipasi petani dalam kelompok tani

2. Untuk melihat penggunaan faktor-faktor produksi, apakah sudah mencapai efisien secara harga yaitu dilakukan hipotesis sebagai berikut :

Efisiensi harga, yaitu perbandingan nilai produksi marjinal (MVP) dengan biaya input marjinal (MIC) atau harga input (Pxi). Secara matematik dirumuskan sebagai berikut

$$
\frac{M V P x i}{P x i}=1, \quad \text { karena, } \frac{M V P x i}{P x i}=k, \text { maka } \mathrm{k}=1
$$

3. Untuk mengetahui faktor-faktor yang mempengaruhi keuntungan usahatani jambu mete digunakan fungsi keuntungan yang dinormalkan secara matematik dirumuskan sebagai berikut :

$\ln \pi=\ln A+b_{1} \ln X_{1}+b_{3} \ln X_{2}+b_{3} \ln X_{3}+b_{4} \ln X_{4}+b_{5} \ln X_{5}+b_{6} \ln X_{6}$

Keterangan:

$\pi \quad=$ keuntungan yang dinormalkan dengan harga output

$\mathrm{X}_{1} \quad$ = upah tenaga kerja yang dinormalkan

$\mathrm{X}_{2} \quad$ = Harga pupuk Urea yang dinormalkan.

$\mathrm{X}_{3} \quad$ = Harga pupuk TSP yang dinormalkan

$\mathrm{X}_{4} \quad$ = Harga pupuk $\mathrm{KCl}$ yang dinormalkan

$\mathrm{X}_{5} \quad$ = harga herbisida yang dinormalkan

$\mathrm{X}_{6} \quad=$ luas lahan (faktor produksi tetap)

$\mathrm{A} \quad=$ intercep

$b_{1} \ldots b_{6}=$ koefisien regresi (parameter yang ditaksir) 
4. Untuk mengetahui faktor-faktor yang mempengaruhi margin pemasaran gelondong jambu mete dianalisis kuadrat terkecil (OLS).

$$
\begin{aligned}
\mathrm{Ym}=\mathrm{a}+\mathrm{b}_{1} \mathrm{X}_{1}+\mathrm{b}_{2} \mathrm{X}_{2} & +\mathrm{b}_{3} \mathrm{X}_{3}+\mathrm{U} \\
\text { Keterangan: } \quad \mathrm{Ym} & =\text { Margin pemasaran } \\
\mathrm{X}_{1} & =\text { Harga di tingkat produsen } \\
\mathrm{X}_{2} & =\text { Jumlah tahap yang dilalui, } \\
\mathrm{X}_{3} & =\text { Volume produksi } \\
\mathrm{a} & =\text { intercep, } \\
\mathrm{b}_{1}-\mathrm{b}_{3} & =\text { koefisien regresi } \\
\mathrm{u} & =\text { kesalahan }
\end{aligned}
$$

5. Diduga bahwa semakin panjang saluran pemasaran jambu mete maka saluran tersebut tidak efisien. Pengujian dilakukan dengan membuktikan bahwa indeks efisiensi pemasaran dari saluran-saluran pemasaran yang ada baik semuanya atau salah satu berbeda nyata dengan nol

$\mathrm{Ho}=\mathrm{Xi}=0$

$\mathrm{Hi}=$ Tidak semua $\mathrm{Xi}$ sama dengan nol

dimana : Xi = Indeks efisiensi pemasaran semua saluran.

$$
\text { F hitung }=\frac{E M S}{R M S}=\frac{E S S /(k-1)}{R S S /(N-k)}
$$

\section{HASIL DAN PEMBAHASAN}

\subsubsection{Analisis Fungsi Produksi}

Melalui analisis regresi berganda dengan fungsi produksi Cobb Douglas diperoleh nilai koefisien regresi untuk semua faktor yang mempengaruhi produksi jambu mete.

Hasil analisis regresi tersebut menunjukkan bahwa setiap kenaikan luas lahan $\left(\mathrm{X}_{1}\right) 1 \%$, maka produksi gelondong jambu mete akan naik 0,39261\%; populasi tanaman $\left(\mathrm{X}_{2}\right)$ naik $1 \%$ maka produksi gelondong jambu mete akan naik sebesar $0,80598 \%$; partisipasi petani dalam kelompok tani $\left(\mathrm{X}_{11}\right)$ naik $1 \%$ akan menaikan produksi gelondong jambu mete sebesar $0,11863 \%$; jumlah tenaga kerja $\left(\mathrm{X}_{4}\right)$ naik $1 \%$ maka produksi gelondong jambu mete akan naik sebesar 0,13988\%; pupuk Urea $\left(X_{5}\right)$ naik $1 \%$ akan menaikkan produksi gelondong jambu mete sebesar 0.15069 ; dan setiap kenaikan intensitas penyuluhan $\left(\mathrm{X}_{14}\right)$ naik $1 \%$ maka produksi gelondong jambu mete akan turun sebesar $0,23715 \%$.

Untuk umur tanaman $\left(\mathrm{X}_{3}\right)$, pupuk $\mathrm{KCl}\left(\mathrm{X}_{7}\right)$, herbisida $\left(\mathrm{X}_{8}\right)$, pengalaman petani $\left(\mathrm{X}_{9}\right)$, pendidikan formal $\left(\mathrm{X}_{10}\right)$, jarak dari sarana produksi $\left(\mathrm{X}_{12}\right)$ dan jarak dari kebun $\left(\mathrm{X}_{13}\right)$ mempunyai nilai t-hitung lebih kecil dari t-tabel, meskipun pada taraf kepercayaan $90 \%$. Ini menunjukkan bahwa nilai koefisien untuk variabelvariabel tersebut tidak bermakna. Artinya kenaikan atau penurunan variabelvariabel tersebut tidak berpengaruh nyata terhadap produksi.

Luas lahan mempunyai pengaruh sangat nyata terhadap produksi jambu mete. Penambahan luas lahan 1\% dapat meningkatkan produksi jambu mete sebesar 
0,39261\%. Kuat dugaan karena daerah penelitian mempunyai kondisi ekologi yang betul-betul sesuai (tanah dan iklim). Hasil pengamatan (Abdullah 1990), menyatakan daerah yang paling dekat dengan persyaratan ekologis adalah NTT. Penggunaan luas lahan ini harus diupayakan seefisien mungkin kalau dapat dibatasi namun tetap memberikan penghasilan yang cukup, dalam artian keuntungan tidak menurun (profit loss).

Tabel 1. Estimasi Persamaan Regresi Penggunaan Faktor Produksi Pada Usahatani Jambu Mete di Kabupaten Flores Timur Tahun 1998.

\begin{tabular}{|rlcc|}
\hline No. & \multicolumn{1}{c}{ Variable Independent } & Koefisien Regresi & T-hitung \\
\hline 1. & luas lahan $\left(\mathrm{X}_{1}\right)$ & $0,39261^{* * * *}$ & 3,5779 \\
2. & populasi tanaman $\left(\mathrm{X}_{2}\right)$ & $0,80598^{* * *}$ & 9,1902 \\
3. & umur tanaman $\left(\mathrm{X}_{3}\right)$ & $-0,0049044$ & $-0,061559$ \\
4. & jumlah tenaga kerja $\left(\mathrm{X}_{4}\right)$ & $0,13988^{* *}$ & 1,9621 \\
5. & pupuk Urea $\left(\mathrm{X}_{5}\right)$ & $0,15069^{* *}$ & 2,1487 \\
6. & pupuk KCl $\left(\mathrm{X}_{7}\right)$ & $-0,051258$ & $-0,70709$ \\
7. & herbisida $\left(\mathrm{X}_{8}\right)$ & $-0,12414$ & $-1,1465$ \\
8. & pengalaman petani $\left(\mathrm{X}_{9}\right)$ & $-0,077991$ & $-1,1759$ \\
9. & pendidikan petani $\left(\mathrm{X}_{10}\right)$ & $-0,00087372$ & $-0,022823$ \\
10. & partisipasi petani $\left(\mathrm{X}_{11}\right)$ & $0,11863^{* * *}$ & 2,3997 \\
11. & jarak sarana produksi $\left(\mathrm{X}_{12}\right)$ & $-0,043202$ & $-0,67646$ \\
12. & jarak dari kebun $\left(\mathrm{X}_{13}\right)$ & 0,0068754 & 0,091104 \\
13. & intensitas penyuluhan $\left(\mathrm{X}_{14}\right)$ & $-0,23715^{* *}$ & $-2,0746$ \\
\hline & Constant & 2,7927 & 6,9157 \\
\hline & $\mathrm{R}^{2}$ & 0,8385 & \\
\hline & F-hitung & 44,457 \\
\hline
\end{tabular}

Sumber : Analisis Data Primer, 1998

$* * *$ = sangat nyata pada tingkat kesalahan $1 \%$

** = nyata pada tingkat keslahan $5 \%$

Pembatasan luas lahan harus dikompensasi dengan meningkatkan produktivitasnya. Dengan produktivitas lahan yang meningkat, dalam luas lahan yang sama dapat digunakan sistem usahatani terpadu. Kegiatan usahatani diarahkan dengan skala ekonomi yang melibatkan petani sebanyak mungkin serta luas garapan sesuai yang digarap petani. Dengan cara lain seperti sistem usahatani lorong (alley cropping) yang diarahkan ke daerah-daerah miring dengan tujuan menjaga kelestarian lahan, utamanya mengurangi tingkat erosi, disamping memperbaiki keadaan mikro sekitar tanaman alley.

Populasi tanaman berpengaruh sangat nyata terhadap produksi jambu mete dengan kontribusi $0,80598 \%$ setiap persen tambahan populasi tersebut. Hal ini menunjukkan bahwa penambahan populasi tanaman akan manambah produksi yang mengakibatkan lahan garapan untuk usahatani terbatas.

Partisipasi petani mempunyai pengaruh sangat nyata. Setiap kenaikan $1 \%$ partisispsi petani dalam kelompok tani dapat menyebabkan tambahan $0,11863 \%$ produksi jambu mete. Hal ini mengindikasikan bahwa kesungguhan petani dalam kelompok tani relatif baik, apalagi dengan adanya kerja sama dalam bentuk gotong 
royong yang senantiasa dilakukan petani setempat. Dengan gotong royang yang nantinya akan bergilir bagi setiap petani dalam kelompok tani akan memberi nilai tambah utamanya nilai ekonomis tinggi karena mengurangi pengeluaran bagi petani. Mengingat hal ini penting maka kelompok tani perlu ditingkatkan untuk mencapai produktivitas jambu mete.

Tenaga kerja berpengaruh nyata terhadap produski jambu mete dengan kontribusi $0,13988 \%$. Setiap kenaikan $1 \%$ penggunaan tenaga kerja menyebabkan tambahan produksi jambu mente sebesar $0,13988 \%$. Hal ini menunjukkan bahwa penggunaan tenaga kerja harus diefisienkan dengan cara meningkatkan produktivitas atau pengurangan secara kuantitas. Peningkatan produktivitas tenaga kerja dapat dipacu dengan pemberian insentif gaji. Penambahan insentif gaji harus mengacu pada profit oriented (orientasi keuntungan) yaitu tambahan gaji yang diberikan harus lebih rendah dari tambahan revenue (penerimaan) yang dihasilkan sehingga tidak menimbulkan profit loss. Alternatif lain yaitu pengurangan tenaga kerja jelas akan mengurangi biaya produksi jambu mete. Berkurangnya biaya pada kondisi revenue yang tetap akan meningkatkan keuntungan.

Pupuk Urea mempunyai pengaruh nyata. Setiap kenaikan $1 \%$ penggunaan pupuk Urea dapat menyebabkan tambahan $0,15069 \%$ produksi. Hal ini karena unsur hara sangat penting bagi tanaman. Tanaman mempunyai jăringan yang dibangun dari karbohitrad, protein, lemak dan enzim, sehingga untuk membentuk jaringan agar berfungsi maka perlu unsur hara. Jika tanah dipakai secara terus mênerus untuk pertanaman tanpa diberi pupuk atau tidak ditambah unsur hara, maka produksinya akan rendah karena hanya bergantung pada terjadinya penambahan unsur hara secara alami yang pada hakekatnya sudah terbatas ketersediaannya. Dengan demikian pemberian pupuk sangat penting untuk meningkatkan produksi.

Berbeda dengan variabel-variabel terdahulu, intensitas penyuluhan mempunyai pengaruh nyata dengan korelasi negatif. Tambahan intensitas penyuluhan $1 \%$ akan mengurangi produksi sebesar $0,23715 \%$. Hal ini diduga karena intensitas penyuluhan yang dilakukan tidak efektif.

Tingkat pendidikan petani tidak berpengaruh dimungkinkan karena pendidikan yang rata-rata hampir sama yaitu hampir semua petani contoh adalah tamatan SD. Sehingga pendidikan mungkin tidak terlalu penting dan alternatifnya adalah pendidikan yang sifatnya non formal seperti pendidikan ketrampilan khusus.

\subsubsection{Efisiensi Alokatif}

Test efisiensi harga (allocative efficiency) secara tradisional didekati dengan menyamakan nilai produk marginal dengan harga input (Opportunity cost) atau apabila ratio nilai produk marginal dengan harga input sama dengan satu dikatakan usahatani sudah mengalokasikan masukan secara efisien.

Penggunaan pupuk Urea dan curahan tenaga kerja belum mencapai tingkat yang efisien, terlihat dari nilai t-hitung di atas t-tabel yang artinya tidak sama dengan satu maka NPM yang masih jauh lebih tinggi dari pada harga pupuk Urea dan curahan tenaga kerja. Dengan demikian masih ada peluang untuk meningkatkan penerimaan dengan cara menambah pupuk Urea dan curahan tenaga kerja ke tingkat yang efisien. 
Tabel 2. Estimasi Efisiensi Penggunaan Input pada Usahatani Jambu Mete di Kabupaten Flores Timur Tahun 1998.

\begin{tabular}{|lrrrrr|}
\hline \multicolumn{1}{|c}{ Input } & Harga Input & \multicolumn{1}{c}{ NPM } & \multicolumn{1}{c|}{ k } & \multicolumn{1}{c|}{ t-hitung } & Keterangan \\
\hline Pupuk Urea & $1.000,00$ & $47.172,11$ & 47,17 & $658,38^{* * * *}$ & tidak efisien \\
Pupuk KCl & $1.100,00$ & $-21826,29$ & $-19,84$ & $-287,51^{* * *}$ & tidak efisien \\
Tenaga Kerja & $3.347,08$ & 8924,22 & 2,67 & $23,37^{* * *}$ & tidak efisien \\
Herbisida & $44.842,21$ & $-416748,97$ & $-9,29$ & $-95,07 * * *$ & tidak efisien \\
\hline
\end{tabular}

Sumber: Analisi Data Primer

Sementara pupuk $\mathrm{KCl}$ dan herbisida juga belum mencapai efisien namun arahnya berbeda dengan jenis input lainnya. Nilai input kedua variabel tersebut lebih besar dari pada NPM yang artinya bila ditambah pupuk $\mathrm{KCl}$ dan herbisida justru tidak efisien karena tambahan penerimaan yang didapat dari penambahan pupuk $\mathrm{KCl}$ dan herbisida tidak sebanding dengan harga pupuk $\mathrm{KCl}$ dan herbisda itu sendiri. Maka yang perlu dilakukan adalah mengurangi kuantitas kedua variabel tersebut sampai pada tingkat yang efisien.

\subsubsection{Analisis Fungsi Keuntungan}

Untuk mengestimasi fungsi keuntungan usahatani jambu mete digunakan fungsi regresi linier berganda dengan metode ordinary least square.

Tabel 3. Hasil Analisis Regresi Penggunaan Faktor Keuntungan Pada Usahatani Jambu Mete di Kabupaten Flores Timur Tahun 1998.

\begin{tabular}{|clll|}
\hline No. & Variable Independent & Koefisien Regresi & T-hitung \\
\hline 1. & upah tenaga kerja $\left(\mathrm{X}_{1}\right)$ & 0,30720 & 1,2356 \\
2 & harga pupuk Urea $\left(\mathrm{X}_{2}\right)$ & $-2,2527^{* *}$ & $-2,1124$ \\
3 & harga pupuk TSP $\left(\mathrm{X}_{3}\right)$ & 0,21772 & 0,23792 \\
4 & harga pupuk KCl $\left(\mathrm{X}_{4}\right)$ & $1,7361^{*}$ & 1,4785 \\
5 & harga herbisida $\left(\mathrm{X}_{5}\right)$ & $0,042412^{* * *}$ & 5,2294 \\
6 & luas lahan $(\mathrm{X6})$ & 0,89941 & $-0,70709$ \\
\hline & Constant & 15,171 & 6,8205 \\
\hline & $\mathrm{R}^{2}$ & 0,2506 & \\
\hline
\end{tabular}

Sumber: Analisis Data Primer, 1998

$* * *$ = sangat nyata pada tingkat kesalahan $1 \%$

$* *$ = nyata pada tingkat kesalahan $5 \%$

* = kurang nyata pada tingkat kesalahan $10 \%$

Hasil analisis regresi menunjukkan bahwa setiap kenaikan harga pupuk Urea $\left(\mathrm{X}_{2}\right) 1 \%$, maka keuntungan usahatani jambu mente akan turun 2,2527\%. Hal ini karena biaya produksi yang dikeluarkan petani untuk membeli input tersebut naik (krisis moneter) sehingga dampak selanjutnya adalah keuntungan petani semakin kecil. Doll dan Orazem (1984) menyatakan bahwa keuntungan ditentukan oleh jumlah output, harga output dan biaya produksi. Pendapat senada (Soekartawi, 1994), bahwa harga variabel faktor produksi bibit, pupuk dan pestisida mempunyai 


\section{AGRO EKONOMI}

hubungan negatif dengan keuntungan, yang berarti makin tinggi biaya yang dikeluarkan untuk membeli input produksi maka keuntungan yang akan diterima semakin kecil.

Koefisien regresi harga herbisida sebesar $0,042412 \%$ dan berpengaruh terhadap keuntungan usahatani jambu mete pada tingkat kesalahan $1 \%$. Sementara setiap kenaikan $1 \%$ harga pupuk $\mathrm{KCl}$, maka keuntungan usahatani jambu mete akan naik sebesar $1,7361 \%$. Hal ini disebabkan karena penggunaan input dan biaya produksi yang dikeluarkan menjadi lebih efisien, sehingga kenaikan herbisida dan pupuk $\mathrm{KCl}$ akan meningkatkan keuntungan.

\subsubsection{Perkembangan Harga Jambu Mete}

Harga adalah satu-satunya unsur dalam bauran pemasaran yang menghasilkan pendapatan penjualan atau harga merupakan jumlah uang yang dibutuhkan untuk mendapatkan sejumlah barang.

Saluran pemasaran satu merupakan saluran pemasaran gelondong jambu mente yang paling panjang. Untuk mendapatkan keuntungan pedagang perantara menekan harga di tingkat produsen (petani). Sehingga petani memperoleh tingkat harga dan bagian yang rendah pula tabel 4 .

Tabel 4. Perkembangan Harga Gelondong Mete dari Produsen Sampai Konsumen yang Melalui Saluran Pemasaran I

\begin{tabular}{|c|c|c|c|}
\hline No. & Keterangan & $\mathrm{Rp} / \mathrm{kg}$ & $\%$ \\
\hline 1. & $\begin{array}{l}\text { Harga di tingkat petani } \\
\text { Biaya pada pedagang pengumpul kecil } \\
\text { - Transportasi } \\
\text { - Timbang } \\
\text { - Angkut } \\
\text { - Penyusutan } \\
\text { Jumlah Biaya } \\
\text { Keuntungan }\end{array}$ & $\begin{array}{r}8.558,33 \\
30,00 \\
22,30 \\
25,35 \\
92,55 \\
170,20 \\
115,30 \\
\end{array}$ & $\begin{array}{l}90,23 \\
0,32 \\
0,24 \\
0,27 \\
0,98 \\
1,80 \\
1,22 \\
\end{array}$ \\
\hline 2. & $\begin{array}{l}\text { Harga di pedagang pengumpul kecil } \\
\text { Biaya pada pedagang pengumpul menengah } \\
\text { - Transportasi } \\
\text { - Angkut } \\
\text { - Penyusutan } \\
\text { Jumlah Biaya } \\
\text { Keuntungan }\end{array}$ & $\begin{array}{r}8.729,16 \\
27,75 \\
20,25 \\
90,25 \\
138,25 \\
157,73 \\
\end{array}$ & $\begin{array}{l}92,03 \\
0,30 \\
0,21 \\
0,95 \\
1,46 \\
1,66 \\
\end{array}$ \\
\hline 3. & $\begin{array}{l}\text { Harga di pedagang pengumpul menengah } \\
\text { Biaya pada pedagang pengumpul besar } \\
\text { - Kepak } \\
\text { - Penyusutan } \\
\text { Jumlah Biaya } \\
\text { Keuntungan } \\
\end{array}$ & $\begin{array}{r}9.120,25 \\
15,35 \\
88,80 \\
104,15 \\
226,91 \\
\end{array}$ & $\begin{array}{r}96,15 \\
0,16 \\
0,94 \\
1,10 \\
2,39 \\
\end{array}$ \\
\hline 4. & Harga di pedagang pengumpul besar & $9.485,33$ & 100,00 \\
\hline
\end{tabular}

Sumber: Analisis Data Primer 
Tabel tersebut di atas menunjukkan bahwa persentase perbandingan harga yang diterima petani dengan harga yang dibayar konusmen akhir (bagian petani sebesar 90,23 persen).

Sementara total yang dikeluarkan oleh semua lembaga pemasaran pada saluaran pemasaran I ini sebesar Rp 412,60 per kg. Dan total keuntungan yang diperoleh oleh semua lembaga pemasaran untuk saluran I ini adalah Rp 499,94 per $\mathrm{kg}$.

Perkembangan harga gelondong jambu mete dari petani sampai konsumen akhir pada saluran pemasaran bentuk II ditunjukkan pada tabel 5 .

Tabel 5. Perkembangan Harga Gelondong Mete dari Produsen Sampai Konsumen yang Melalui Saluran Pemasaran II

\begin{tabular}{|c|l|c|c|}
\hline No. & \multicolumn{1}{|c|}{ Keterangan } & $\mathrm{Rp} / \mathrm{kg}$ & $\%$ \\
\hline 1. & Harga di tingkat petani & $8.700,00$ & 91,69 \\
& Biaya pada pedagang pengumpul menengah & & \\
& - Transportasi & 29,25 & 0,31 \\
& - Angkut & 25,15 & 0,27 \\
& - Penyusutan & 149,80 & 1,58 \\
& Jumlah Biaya & 204,20 & 2,15 \\
& Keuntungan & 216,43 & 2,28 \\
\hline 2. & Harga di pedagang pengumpul menengah & $9.125,00$ & 96,17 \\
& Biaya pada pedagang pengumpul besar & & \\
& - Kepak & 15,35 & 0,16 \\
& - Penyusutan & 88,80 & 0,94 \\
& Jumlah Biaya & 104,15 & 1,10 \\
& Keuntungan & 220,20 & 2,32 \\
\hline 3. & Harga di pedagang pengumpul besar & $9.488,33$ & 100,00 \\
\hline
\end{tabular}

Sumber: Analisis Data Primer

Dari tabel 5. diketahui bahwa bagian harga yang diterima petani pada saluran II yang juga merupakan saluran panjang adalah 91,69 persen. Berhubung masih merupakan saluran panjang, maka harga di tingkat petani tetap ditekan sehingga bagian harga yang diterima petani masih lebih rendah dibandingkan dengan bagian harga yang diterima petani pada saluran pendek.

Total biaya yang dikeluarkan oleh semua lembaga pemasaran pada saluran II ini adalah sebesar $\mathrm{Rp} 308,35$ per $\mathrm{kg}$. Sementara total keuntungan yang diperoleh oleh scmua lembaga pemasaran yang terlibat pada saluran II adalah sebesar Rp 436,63 per $\mathrm{kg}$.

Untuk perkembangan harga dari petani sampai kosumen pada saiuran pemasaran bentuk III dapat dilihat pada tabel 6 . 
Tabel 6. Perkembangan Harga Gelondong Mete dari Produsen Sampai Konsumen yang Melalui Saluran Pemasaran III

\begin{tabular}{|l|l|c|c|}
\hline No. & \multicolumn{1}{|c|}{ Keterangan } & Rp/kg & $\%$ \\
\hline 1. & Harga di tingkat petani & $8.746,15$ & 92,70 \\
& Biaya pada pedagang pengumpul besar & & \\
& - Kepak & 15,35 & 0,16 \\
& - Penyusutan & 290,71 & 3,08 \\
& Jumlah Biaya & 306,06 & 3,24 \\
& Keuntungan & 432,40 & 4,58 \\
\hline 2. & Harga di pedagang pengumpul besar & $9.434,62$ & 100,00 \\
\hline
\end{tabular}

Sumber: Analisis Data Primer

Terlihat bahwa bagian harga yang diterima petani pada saluran III yang merupakan saluran pendek adalah 92,70 persen. Kerena merupakan saluran pendek, maka harga di tingkat petani dapat ditekan sehingga bagian harga yang diterima petani dapat lebih tinggi dibandingkan dengan bagian harga yang diterima petani pada saluran panjang.

Total biaya yang dikeluarkan oleh semua lembaga pemasaran bentuk III ini adalah sebesar Rp 306,06 per kg. Scdangkan total keuntungan yang diperoleh oleh semua lembaga pemasaran yang terlibat pada saluran III adalah sebesar Rp 432,40 per $\mathrm{kg}$.

\subsubsection{Biaya Pemasaran}

Besarnya biaya yang dikeluarkan bagi tiap saluran pemasaran selalu berbedabeda. Dengan demikian semakin panjang saluran pemasaran maka jumlah biaya yang dikeluarkan akan semakin bertambah tabel 7 .

Tabel 7. Besarnya Biaya yang Dikeluarkan Pedagang Perantara di Berbagai Saluran Pemasaran $(\mathrm{Rp} / \mathrm{Kg})$

\begin{tabular}{|c|c|c|c|c|}
\hline Saluran & PPK & PPM & PPB & Jumlah \\
\hline I & 170,20 & 138,25 & 104,15 & 412,60 \\
\hline II & - & 204,20 & 104,15 & 308,35 \\
\hline III & - & - & 306,06 & 306,06 \\
\hline
\end{tabular}

Sumber: Analisis Data Primer

Tabel tersebut di atas menunjukkan bahwa biaya pemasaran yang paling banyak adalah pada saluran I yang merupakan saluran panjang. Sementara pada saluran III yang merupakan saluran pemasaran pendek lebih rendah dibandingkan dengan saluran I dan II.

Biaya pemasaran untuk setiap saluran tidak sama. Secara rinci besarnya biaya yang dikeluarkan berdasarkan jenis kegiatan dapat disajikan pada tabel 8 . 
Tabel 8. Rincian Biaya Pemasaran Gelondong Jambu Mete Berdasarkan Jenis Kegiatan di Kabupaten Flores Timur Tahun 1998

\begin{tabular}{|c|c|c|c|c|c|c|}
\hline \multirow{3}{*}{ Jenis Kegiatan } & \multicolumn{6}{|c|}{ Saluran Pemasaran Gelodong Jambu Mente } \\
\hline & \multicolumn{2}{|c|}{$\mathrm{I}$} & \multicolumn{2}{|c|}{ II } & \multicolumn{2}{|c|}{ III } \\
\hline & $\mathrm{Rp} / \mathrm{kg}$ & $\%$ & $\mathrm{Rp} / \mathrm{kg}$ & $\%$ & $\mathrm{Rp} / \mathrm{kg}$ & $\%$ \\
\hline Pengangkutan & 57,75 & 13,99 & 29,25 & 9,48 & - & - \\
\hline Tenaga & 45,60 & 11,52 & 25,15 & 8,12 & - & - \\
\hline Timbang & 22,30 & 5,40 & - & - & - & - \\
\hline Penyusutan & 271,60 & 65,83 & 238,60 & 77,38 & 290,71 & 94,98 \\
\hline Pengepakan & 15,35 & 3,72 & 15,35 & 4,98 & 15,35 & 5,02 \\
\hline Jumlah & 412,60 & 100,00 & 308,35 & 100,00 & 306,06 & 100,00 \\
\hline
\end{tabular}

Persentase biaya penyusutan terlihat semakin tinggi dengan semakin pendeknya saluran pemasaran.

\subsubsection{Keuntungan Pedagang}

Keuntungan pedagang merupakan imbalan atas jasa yang dilakukan selama melakukan proses pemasaran. Keuntungan pedagang berbeda-beda antara pedagang yang satu dengan pedagang yang lainnya. Hal ini diduga karena jasa yang telah dilakukan oleh para pedagang tersebut berbeda beda.

Besarnya keuntungan pedagang dari berbagai jenis saluran pemasaran gelondong jambu mente dapat dilihat pada tabel berikut:

Tabel 9. Keuntungan Pedagang Perantara Pada Berbagai Saluran Pemasaran Gelondong Jambu Mete Di Kabupaten Flores Timur Tahun 1998 (Rp)

\begin{tabular}{|c|c|c|c|c|}
\hline Saluran & PPK & PPM & PPB & Jumlah \\
\hline I & 115,30 & 157,73 & 226,91 & 499,94 \\
\hline II & - & 216,43 & 220,20 & 436,63 \\
\hline III & - & - & 432,40 & 432,40 \\
\hline
\end{tabular}

Sumber: Analisi Data Primer

Keterangan : PPK = Pedagang Pengumpul Kecil

PPM = Pedagang Pengumpul Menengah

$\mathrm{PPB}=$ Pedagang Pengumpul Besar

Dari tabel terlihat keuntungan terbesar yang diperoleh pedagang adalah pada saluran I yaitu sebesar 499,94 per kg. Diduga karena pada saluran I jumlah lembaga pemasarannya lebih banyak sehingga total keuntungannya paling besar.

\subsubsection{Margin Pemasaran}

Besarnya margin pemasaran untuk pedagang perantara dipengaruhi oleh unsur-unsur biaya pemasaran dan keuntungan pemasaran sebagai imbalan atas jasa pedagang perantara dalam memasarkan gelondong jambu mete. Rincian margin pemasaran pada berbagai saluran pemasaran tabel 10 . 
Tabel 10. Besar Margin Pemasaran Pada Beberapa Pedagang di Berbagai Saluran Pemasaran Gelondong Jambu Mete di Kabupaten Flores Timur Tahun 1998 (Rp/kg)

\begin{tabular}{|c|c|c|c|c|}
\hline Saluran & PPK & PPM & PPB & Jumlah \\
\hline I & 170,83 & 391,09 & 365,08 & 927,00 \\
\hline II & - & 425,00 & 363,33 & 788,33 \\
\hline III & - & - & 688,47 & 688,47 \\
\hline
\end{tabular}

Sumber: Analisis Data Primer

Pada tabel terlihat bahwa margin pemasaran yang paling besar adalah pada saluran I yakni $\mathrm{Rp} 927,00$ per $\mathrm{kg}$ dan yang terkecil pada saluran III yakni Rp 688,47 per $\mathrm{kg}$. Kuat dugaan disebabkan pada saluran I terdapat tiga pedagang perantara sedangkan pada saluran III hanya terdapat satu pedagang perantara. Disamping itu pada saluran I membutuhkan biaya untuk pengangkutan yang lebih tinggi karena jarak antara produsen dan konsumen yang begitu jauh dibandingkan dengan saluran yang lainnya.

Tabel 11. Hasil Analisis Regresi Faktor yang Mempengaruhi Margin Pemasaran Jambu Mete di Kabupaten Flores timur Tahun 1998.

\begin{tabular}{|llcc|}
\hline No. & \multicolumn{1}{c}{ Variable Independent } & Koefisien Regresi & T-hitung \\
\hline 1. & harga pada produsen $\left(\mathrm{X}_{1}\right)$ & $-5,6868^{* * *}$ & $-2,0045$ \\
2 & jumlah saluran $\left(\mathrm{X}_{2}\right)$ & 0,0806 & 1,2871 \\
3 & volume produksi $\left(\mathrm{X}_{3}\right)$ & $0,0613^{*}$ & 1,4592 \\
& constanta & 57,760 & 2,2335 \\
& $\mathrm{R}^{2}$ & 0,5195 & \\
& F-hitung & 12,9774 & \\
\hline
\end{tabular}

Sumber : Analisis Data Primer, 1998

** = nyata pada tingkat kesalahan $5 \%$

* = kurang nyata tingkat $10 \%$

Berdasarkan tabel 11 dapat diketahui bahwa harga di tingkat produsen, jumlah saluran yang dilalui, volume produksi, secara bersama-sama berpengaruh sangat nyata terhadap margin pemasaran (Ym) pada taraf 99\%. Hal ini ditunjukkan oleh nilai $F$ hitung yang lebih besar dari $F$ tabel.

Berdasarkan nilai koefisien determinasi $\left(\mathrm{R}^{2}\right)$ dapat diketahui bahwa variansi dari harga produsen, jumlah saluran dan volume produksi dapat menjelaskan $51,95 \%$ terhadap variansi margin pemasaran $(\mathrm{Ym})$. Variasi margin pemasaran yang tidak dapat dijelaskan oleh variabel-variabel independen (bebas) tersebut sebesar $48,05 \%$. Hal ini disebabkan oleh faktor lain yang tidak masuk dalam model.

Hasil analisis regresi menunjukkan bahwa setiap kenaikan harga jambu mete pada tingkat produsen $1 \%$, maka margin pemasaran akan turun sebesar $5,6868 \%$; dan volume produksi naik $1 \%$ maka margin pemasaran akan naik sebesar $0,61318 \%$. 
Sementara jumlah saluran yang dilalui mempunyai nilai t-hitung labih kecil dari t-tabel, walaupun pada tingkat kepercayaan $90 \%$. Ini berarti kenaikan variabel tersebut tidak berpengaruh nyata terhadap margin pemasaran.

Harga di tingkat produsen mempunyai pengaruh nyata terhadap margin pemasaran. Ini menunjukkan harga beli pada tingkat produsen merupakan variabel bebas yang paling berpengaruh dalam menentukan terbentuknya harga jual gelondong jambu mete. Kuat dugaan karena harga beli merupakan biaya pokok yang terbesar yang harus dikeluarkan dalam perdagangan dimana kedudukannya dapat disamakan dengan biaya produksi. Adanya korelasi negatif diduga karena harga gelondong yang dibeli pada setiap periode relatif hampir sama artinya pada kondisi tertentu harga gelondong bisa naik atau turun dengan variasi harga yang sama.

\subsubsection{Efisiensi Pemasaran}

Untuk mengetahui saluran pemasaran mana yang lebih efisien dari saluran pemasaran yang ada dapat dihitung dengan menggunakan indeks efisiensi yakni mencakupi indeks efisiensi teknis dan indeks efisiensi ekonomis.

Indeks efisiensi ekonomis merupakan besarnya keuntungan yang dihasilkan per satuan biaya yang dikeluarkan. Saluran pemasaran dikatakan efisien secara ekonomis apabila mempunyai indeks efisiensi yang besar. Untuk mengetahui besarnya indeks efisiensi teknis dan efisiensi eknomis pemasaran gelondong jambu mete pada masing-masing saluran pemasaran seperti ditunjukkan pada tabel 12 .

Tabel 12. Indeks Efisiensi Teknis dan Efisiensi Ekonomis Pemasaran Gelondong Jambu Mete pada Masing-masing Saluran Pemasaran di Kabupaten Flores Timur Tahun 1998

\begin{tabular}{|c|c|c|}
\hline \multirow{2}{*}{ Saluran } & \multicolumn{2}{|c|}{ Efisiensi Pemasaran } \\
\cline { 2 - 3 } & Teknsi & Ekonomis \\
\hline I & 11,5217 & 1,2167 \\
\hline II & 13,0440 & $1,4280^{* *}$ \\
\hline III & $19,4600^{* *}$ & $1,4277^{* *}$ \\
\hline F-hitung & $29,9864 * * *$ & $8,8436 * * *$ \\
\hline F-tabel & 7,31 & 7,31 \\
\hline
\end{tabular}

Sumber: Analisis Data Primer

Keterangan :

$$
\begin{aligned}
& * * *=\text { sangat nyata pada tingkat kesalahan } 1 \% \\
& * *=\text { nyata pada tingkat kesalahan } 5 \%
\end{aligned}
$$

Saluran III yang merupakan saluran pendek mempunyai nilai efisiensi teknis yang lebih besar dan nilai efisiensi ekonomis yang relatif lebih besar dibandingkan dengan saluran I dan saluran II yang merupakan saluran pemasaran panjang. Ini menunjukkan bahwa meskipun saluran III adalah saluran pemasaran yang pendek tetapi tidak efisien walaupun secara statistik berpengaruh nyata. 


\section{AGRO EKONOMI}

\section{KESIMPULAN DAN SARAN}

\subsection{Kesimpulan}

Dari 14 variabel yang diduga mempengaruhi produksi jambu mete ternyata ada enam variabel yang berpengaruh. Lima di antaranya berpengaruh positif dan satunya berpengaruh negatif. Sedangkan delapan faktor input yang pengaruhnya tidak nyata terhadap produktivitas jambu mente. Faktor input yang berpengaruh nyata adalah: luas lahan, populasi tanaman, jumlah tenaga kerja, pupuk Urea, partisipasi petani, dan intensitas penyuluhan. Keenam peubah tersebut berpengaruh terhadap produktivitas jambu mente masing-masing dengan koefisien regresi : $0.39261 ; 0,80598 ; 0,13988 ; 0,15069 ; 0,11863$; dan $-0,23715$. Umur tanaman, pupuk $\mathrm{KCl}$, herbisida pengalaman petani, pendidikan, jarak dari sarana produksi, dan jarak dari kebun, meskipun pada taraf kepercayaan $90 \%$ dalam uji thitung tetap tidak bermakna. Artinya kenaikan atau penurunan variabel-variabel tersebut tidak berpengaruh nyata produksi.

Penggunaan pupuk Urea, $\mathrm{KCl}$, tenaga kerja dan herbisida di Flores Timur secara alokatif belum mencapai efisien.

Keuntungan usahatani jambu mente di Flores Timur sangat dipengaruhi oleh harga pupuk Urea, harga pupuk $\mathrm{KCl}$, dan harga herbisida, sedangkan upah tenaga kerja, harga pupuk TSP, dan luas lahan tidak berpengaruh.

Pada keragaan pasar petani gelondong jambu mete di Kabupaten Flores Timur ada tiga macam. Ketiga macam saluran tersebut adalah: (1). PetaniPedagang Pengumpul Kecil - Pedagang Pengumpul Menengah - Pedagang Pengumpul Besar - Ekspor, (2). Saluran II: Petani - Pedagang Pengumpul Menengah - Pedagang Pengumpul Besar - Ekspor, (3). Saluran III: Petani Pedagang Besar - Ekspor.

Meskipun saluran pemasaran III adalah saluran pemasaran pendek tetapi tidak efisien walaupun secara statistik berpengaruh nyata. Sehingga berbanding terbalik dengan hipotesa yang selalu mengatakan bahwa semakin pendek suatu saluran pemasaran maka saluran tersebut adalah semakin efisien.

\subsection{Saran}

Perlunya peningkatan kerjasama antara instansi terkait utamanya Badan Litbang Pertanian setempat (BPTP) dan Universitas untuk memperoleh rekomendasi yang bersifat spesifik lokasi serta peningkatan kemampuan managerial petani.

Untuk lebih memperbaiki posisi petani di pasar, diperlukan upaya yang menyangkut aspek penanganan pasca panen oleh petani dan aspek penemuan harga (price discovery). Aspek penanganan pasca panen yang dimaksud berupa penumbuhan kembali industri pengolahan kacang mente di tingkat petani agar petani dapat menikmati bagian harga yang diterima (farmer's share) yang lebih besar. Aspek penemuan harga, perlu dipikirkan agar ada perbedaan harga antar kualitas sehingga akan merangsang petani untuk memperbaiki kualitas produk mente siap jual baik melalui sistem produksi maupun sortasi pasca panen, dan memperlancar penyampaian informasi harga posisi tawar menawar petani di pasar semakin baik. 


\section{AGRO EKONOMI}

\section{DAFTAR PUSTAKA}

Arshad, F.M., 1980. The Integration of Palm Oil Market in Penisular Malaysia, Indian Journal Agricultur Development Council Inc. New York.

Abdullah, A dan Irsal Las, 1985. Peta Kesesuian Iklim dan Lahan Untuk pengembangan Tanaman Jambu Mete di Indonesia, Departemen Pertanian Badan Litbang Pertanian 1985.

Doll, J.L. and F. Orazem, 1984. Production Economics, Theori With Apllication. $2^{\text {nd }}$ Edition. John Willey and Sons Inc,. New York.

Ditjenbun, 1991. Pengembangan Jambu Mente dan Prospeknya di Masa Mendatang, Direkktorat Jendral Perkebunan Departemen Pertanian RI, Jakarta.

Debertin, David L., 1986. Agricultural Production Economics. Mac Millan Publishing Company, New York.

Downey, W. D., and W. Erickson, 1992. Agribusiness Management (Terjemahan) Penerbit Erlangga, Jakarta.

Kohl, R.L. and W.D. Downey, 1972. Marketing of Agricultural Product, Mac Millan Publishing co-New York.

Masyhuri, 1994. Manajemen Agribisnis. Program Studi Ekonomi Pertanian. Program Pasca Sarjana, Universitas Gadjah Mada Yogyakarta.

Rashid, A., and Chandhry, Aslam, 1973. Marketing Efficiency in Theory and Practice. ADC Teaching Forum Agriculture Development Council Inc. New York.

Soekartawi, 1990. Teori Ekonomi Produksi Dengan Pokok Bahasan Analisis Fungsi Cobb-Dauglass, Rajawali, Jakarta.

Widodo, S., 1989. Production Effeceincy of Rice Farmers In Java Indonesia. Gadjah Mada University Press Yogyakarta.

Yotopoulus, Pan, A., and Lau, L.J., 1973. A Test for Relative Efficiency and Application Indian Agriculture. The American Economic Reviw I. Vol. 63 N0. 1P. 214-223. 